\title{
Toponímia akwe-xerente: considerações acerca dos nomes de lugares da área indígena
}

\author{
Akwe-xerente toponymy: considerations about indigenous place names in the area
}

\author{
Kênia Mara de Freitas SIQUEIRA* \\ Universidade Estadual de Goiás (UEG)
}

\begin{abstract}
RESUMO: O objetivo deste artigo é apresentar a descrição de alguns topônimos da área indígena xerente considerando para tanto a função que os termos de classe têm na formação de palavras da língua, como elemento genérico organizador de classes. A metodologia pauta-se nas propostas de Dick (1990; 2007), que se desenvolvem mediante um plano onomasiológico de investigação. A partir de um conceito genérico, que pode ser um termo de classe, identificam-se as variáveis possíveis em relação à nomeação dos lugares da língua Akwe-Xerente (Jê).
\end{abstract}

PALAVRAS-CHAVE: Termos de classe. Topônimos. Onomasiologia.

ABSTRACT: The objective of this article is to present the description of some toponyms of the xerente indigenous area, considering for such the function that all class terms have in the formation of words of the language, such as generic element class organizer. The methodology is guided on the proposals of Dick (1990; 2007), which develops by a onomasiological approach of investigation. From a generic concept, that can be a class term, identify themselves the possible variations in relation to naming the places of the Akwe-Xerente language (Jê).

KEYWORDS: Class terms. Toponyms. Onomasiology.

\section{Introdução}

Este artigo constitui, de certa forma, um desdobramento das pesquisas realizadas durante o mestrado e doutorado em Linguística, pela Universidade Federal de Goiás, sobre aspectos referentes ao sistema de classificação nominal da língua Akwe-Xerente ${ }^{1}$ (Jê), pois reconhece que a necessidade de se descrever e documentar línguas ameaçadas de extinção vem, nas últimas décadas, ganhando contornos mais significativos face ao iminente risco de perda da cultura e do conhecimento acumulado pelos povos indígenas. A continuidade de cada uma dessas línguas deve ser assegurada por meio de ações pautadas nos resultados de estudos que visem tanto à descrição da situação sociolinguística, quanto à descrição e à análise dos aspectos linguísticos que as caracterizem como língua de uma determinada família linguística.

Este estudo tem, assim, como objetivo descrever e analisar alguns topônimos Akwe-Xerente, dando continuidade à pesquisa sobre o sistema de classificação nominal da

\footnotetext{
* Doutorado em Letras e Linguística, docente da Universidade Estadual de Goiás (UFG), Curso de Letras, Unidade Universitária de Pires do Rio - GO - Brasil. Email: keniamara@ hotmail.com.

${ }^{1}$ Segundo Rodrigues (1994), língua indígena da família Jê, falada pelo povo de mesmo nome. Os AkweXerente compreendem, atualmente, 4000 pessoas e vivem tanto na região da cidade de Tocantínia, estado do Tocantins, em mais de 59 aldeias, como na própria cidade.
} 
língua. Para tanto, parte-se do conceito de que a toponímia reflete a vivência do homem, como membro do grupo que o acolhe. Nessa perspectiva, a descrição da toponímia xerente pode demonstrar muito da cosmovisão desse povo, pois, o processo de criação de um topônimo é revelador da presença do denominador, que, ao nomear, proporciona ao denotado um caráter legítimo, singular, existencial. A partir deste estudo, pretende-se verificar também como o sistema de classificação nominal desta língua opera para nomear os lugares.

Os procedimentos de pesquisa consistem basicamente no levantamento dos designativos de lugares da área indígena pelos dados de Krieger e Krieger (1994) e na posterior seleção desses nomes, focando nos topônimos que designam os grandes rios, as serras, os morros e alguns nomes de aldeias. Utiliza-se também pesquisa bibliográfica e análise dos dados já sistematizados em pesquisas anteriores.

Este estudo deve compor os trabalhos realizados pelo projeto LIBA - Línguas Indígenas Brasileiras Ameaçadas: Documentação (Análise e Descrição) e Tipologias Sociolinguísticas, CNPq, (processo 50/337/2003-7), grupo de estudos que visa a estudar aspectos sociolinguísticos e linguísticos da comunidade de fala xerente. O LIBA é um projeto interinstitucional que conta com pesquisadores da Universidade Federal de Goiás e da Universidade de Brasília. Assim, este estudo dá continuidade às pesquisas iniciadas por Siqueira (2007), (2009), (2010), além de inserir a Universidade Estadual de Goiás nos trabalhos desenvolvidos nesse projeto.

\section{A nomeação de lugares: motivações étnicas}

Como o intuito deste artigo é apresentar, ainda que de maneira preliminar, o papel dos termos de classe (TC) como uma das coordenadas línguo-motivadoras para o emprego de unidades nominais em função locativa pela comunidade Akwe-Xerente, é necessário repensar alguns conceitos úteis para a descrição do termo usado como topônimo por essa comunidade. Dessa forma, neste item, faz-se também uma revisão dos conceitos de etnia e etnicidade.

Segundo Dick (2010, p. 177), o termo "etnia passa antes pelo crivo de diversos fatores intrincados entre si, como localização espacial do grupo em questão, situação sociológica interna, tipologia das sociedades, práticas culturais características do contato". Dessa maneira, o grupo define-se como um conjunto de indivíduos participantes em sentido étnico que possuem uma visão comum ou próxima àquela geral ou dominante de categorias envolvidas para entender valores que acomodam os conceitos de etnia e etnicidade.

Para Dick (2010, p. 179), o nome de pessoa ou de lugar inscreve-se nesse raciocínio porque é resultado de um "lento elaborar, que traduz e coordena todo processo de escolha ou de doação de um designativo, que se chama apenas, de batismo do lugar, como ocorre, cerimonialmente, com os indivíduos, em geral". Evidentemente, não se trata exatamente do mesmo processo, a não ser pelo aspecto carismático presente em ambas as situações, já que assim como os indivíduos, os lugares, uma vez designados, ganham alma. Tornam-se, conforme Dick (2010), entidades capazes de significar e transmitir a sua significação. Depois da designação, nome e lugar se amalgamam numa mesma identidade, "referencializada e referenciável".

No ato de nomeação, o homem atua como personagem, produzindo, elaborando, significando, fomentando, consciente ou inconscientemente, a produção linguísticocultural de seu grupo. 
Assim, segundo Dick (1990, p. 19) "A toponímia reflete de perto a vivência do homem, enquanto membro do grupo social no qual se insere". Para a autora (1990, p. 31), essa atividade "linguístico-cultural padronizada enseja a elaboração de campos conceituais, correlatos, ilustrativos da realidade objeto".

De acordo com essa ótica, a discussão sobre o processo de nomeação deve observar a intersecção de aspectos que se situam em níveis distintos do percurso gerativo da enunciação de codificação e de decodificação, são eles: o fazer onomasiológico e o fazer semasiológico. Nessa direção, tem-se um percurso gerativo da enunciação que compreende os seguintes passos: (i) a percepção biológica dos objetos do mundo que se transformam em substâncias estruturadas pela cosmovisão do grupo; em seguida, (ii) tem-se a lexemização, que corresponde à produção de significação, isto é, o significante deixa o nível cognitivo e se converte em signo. É pela lexemização que as lexias são atualizadas no discurso realizado. O próximo passo é (iii) a produção discursiva, ou melhor, ocorre a contextualização e a atualização propriamente dita, determinada por uma situação do discurso e da enunciação. Esses parâmetros possibilitam explicar os processos de conceituar e de definir.

Dessa maneira, o conceito situa-se em um nível pré-linguístico (interpretação dos fatos naturais ou culturais), enquanto que a definição está no plano semiótico, pois é, em tese, o resultado da interpretação de unidades lexicais. Segundo Barbosa (1990), conceituar é construir um modelo mental que corresponde a um recorte cultural para escolher a estrutura lexical que melhor pode manifestá-lo. Por outro lado, definir é analisar e descrever o semema linguístico para reconstruir o modelo mental, tendo como ponto de partida a estrutura linguística manifestada.

Pode-se partir do conceito corrente de que a Toponímia é um ramo da Onomástica (disciplina que analisa nomes de pessoas ou lugares), que se preocupa em estudar nomes de lugares. Os topônimos de uma determinada geografia podem ser classificados de acordo com variados aspectos. Segundo Fonseca (1997), há dois critérios básicos: um relacionado à origem linguística e outro à entidade geográfica a que se denomina. Quanto à origem linguística, verifica-se a procedência da emissão linguística que se comporta como topônimo. À entidade geográfica estão vinculadas a cultura e a natureza.

O locativo apresenta um percurso que tem como unidade padrão o termo designativo do acidente geográfico-cultural em Akwe-Xerente cuja maioria é formada pelo termo $k \hat{a}^{2}$ 'água', usado para designar 'rio'. Isso indica que os topônimos cujo sema principal é $k \hat{a}$ denotam praticamente o mesmo biofato (rio, ribeirão, lagoa). Segundo Carvalhinhos (2003), trata-se de uma capa linguística, ou seja, a estrutura profunda do topônimo não muda, o que varia, de acordo com a cultura, é a capa linguística.

Para Dick (1990), a estrutura do topônimo pode ser analisada sob aspectos intra e extralinguísticos. Da relação entre o topônimo e o acidente geográfico, por exemplo, estabelece-se uma interação íntima que compreende também dois elementos básicos, a saber: o elemento (termo) genérico e o elemento específico. $\mathrm{O}$ termo genérico é relativo à entidade geográfica que recebe a denominação. O termo específico - o topônimo propriamente dito - particulariza a noção espacial, identificando-a e singularizando-a entre outras tantas semelhantes. Forma-se assim, um sintagma nominal justaposto ou aglutinado conforme a natureza morfológica da língua.

Por seu alcance multidisciplinar, os estudos toponímicos constituem um caminho possível para o conhecimento do modus vivendi das comunidades linguísticas que ocupam ou já ocuparam um espaço geográfico, histórico e cultural, porque, quando um indivíduo

\footnotetext{
${ }^{2}$ Foneticamente: [ki].
} 
(ou comunidade linguística) atribui um nome a um acidente humano ou físico revelam-se aí, conforme Dick (1990), tendências sociais, políticas, religiosas, culturais.

Nesse sentido, pode-se considerar a função hiperonímica dos termos de classe já descritos por Siqueira (2010) que envolvem por sua vez, muitas noções de base etnossintática, aspectos da formação de palavras, e tantas outras tais como: criatividade, produtividade, lexicalização. De fato, em princípio, os topônimos são formados em nível pós-lexical.

Em relação à semântica, convém ressaltar as associações metafóricas e metonímicas que permeiam o processo de nomear. Segundo Lakoff (1986), essas associações baseiam-se, principalmente, em relações espaciais, temporais e ambientais, muitas vezes tendo o corpo humano como referência (ou índice). Conforme Lakoff e Johnson (1999), as concepções que se têm do mundo são baseadas em experiências concretas e são, em grande parte, definidas por suas características inerentes e por regras contextuais mediadas por metáforas. O estudo da categorização nominal evidencia grupos de propriedades inerentes a essas categorias, isto é, apresenta-se útil para entender a natureza de categorias, muitas vezes expressa pelo uso de classificadores na constituição dos nomes compostos (topônimos).

Langacker (2002) ocupa-se da questão sob o prisma da diversidade linguística, pois acredita que os padrões contemplados numa língua são razoavelmente vistos como constituintes de um estilo cognitivo adequado culturalmente. Tanto assim, que utiliza aportes teóricos da gramática cognitiva para análise de seus dados.

Embora foque seu estudo na diversidade cultural, Langacker (2002) pauta-se na ideia de que há uma base comum subjacente à riqueza de diversidade de estruturas linguísticas encontradas nas línguas do mundo. Os falantes categorizam a realidade porque a realidade ou aspectos dela se projetam na mente desses falantes, assim semantizam ou não o significado de acordo com a imagem que formam da realidade circundante, mediante um recorte linguístico. Dessa forma, entre pensamento, cognição e linguagem, existem os conceitos, as categorias que dada cultura selecionou (e a maneira como selecionou), mostradas ou não na maneira como designam as coisas do mundo físico e cultural.

Os topônimos xerente denominam, principalmente, os rios (hidrotopônimos), ribeirões, lagoas da área indígena, bem como serra e morros (geomorfotopônimos). Entre tantos podem ser citados: Arbo nirkrpo wdê hu 'Ribeirão Vão Grande', Akwẽ nõku 'Ribeirão da aldeia do Rio do Sono', Kakto wdê hurê kâ 'Ribeirão Imburuçu', Ktẽ krãikwa 'Serra do Carmo', Ktẽ krsu kâ 'Rio dos Bois', Ktẽ ka kâ 'Rio do Sono', Hêspo hu kâ 'Ribeirão Bananal', Po rêrkêze 'Morro do Chapéu', Pku ware 'Lagoa da Santa'. As denominações das aldeias apresentam também noções de origem espacial geográfica e de singularidades de cada entidade nomeada: Ro psê zawre Ro psê zawre 'Aldeia Taverna', Nrõ zawi 'Aldeia Porteira', Ktâ krê 'Aldeia Panela-de-Ferro'.

Para descrever e analisar os topônimos da língua é necessário identificar os fatores que constituem a motivação subjacente à escolha do nome do lugar, o que envolve a identificação de fatos culturais, acidentes geográficos, e, ainda, o papel hiperonímico dos termos de classe como organizador linguístico de conjuntos de objetos do mundo.

\section{A metodologia de pesquisa e procedimentos de análise}

A metodologia utilizada nesta pesquisa (empregada em Onomástica) é uma combinação de leituras documentais e de investigação de campo; vincula-se assim, à indução, seguindo os parâmetros etnolinguísticos. O percurso apresentado por Dick (1990) 
desenvolve-se através de um plano onomasiológico de investigação. A partir de um conceito genérico, identificam-se as variáveis possíveis das fontes consultadas.

Sob a ótica linguística, fazem parte dessa etapa do trabalho: o estudo semântico dos compostos, a maioria dos topônimos sendo constituída por nomes compostos por raízes nominais ou nominalizadas (na constituição de alguns compostos há raízes verbais em função adjetiva como se vê nos dados n. 1, 2, 5 e 17); o estudo da estrutura gramatical e a correção fonêmica. Segundo Dick (1990), esse procedimento permite também, de forma sincrônica, que se busquem outras modalidades de apreensão do objeto de estudo, descrevendo ou recuperando o continuum denominativo daquela nomenclatura.

O método indutivo, por outro lado, possibilita a elaboração de hipóteses de trabalho, construídas ao longo das descrições onomásticas. Confirmadas, elas servem de subsídio para comprovar as hipóteses levantadas acerca dos topônimos como índice para se compreender questões sociais, históricas, culturais dos lugares em questão. Os dados são relacionados em fichas, observando os aspectos: aldeia, rio, córregos, morro, serra, significação original e estrutura morfológica, ressaltando o caráter organizador do termo de classe.

Para Aikhenvald (2000), os termos de classe estão na base da língua, atuam na classificação de uma série de morfemas que vão, por sua vez, participar da origem lexical da língua e são quase sempre explicados mediante a análise de pequenos grupos de exemplos. Os processos em que são usados nem sempre são totalmente explicitados, haja vista o caráter de formação de palavras em nível pós-lexical. Um dos domínios mais comuns dos termos de classe é o das plantas, com o qual as línguas diferenciam características entre árvores, frutos, semente, raiz.

Consideradas as propostas de Delancey (1986); Mithun (1986); Matthews (1993); Sousa Filho (2007) para o conceito e a descrição de raízes nominais que funcionam como termos de classe (TC), propõe-se a análise de topônimos que contenham alguma das raízes: (wa) du 'capim', nfõ (coco) 'palmáceas', ki 'água', kti 'animais comestíveis', ude 'árvore', $Z \dot{i}$ 'sementes'. Como já foi dito, os termos de classe em Akwe-Xerente funcionam como uma espécie de hiperônimo constituindo um conjunto mais amplo, no qual muitos outros objetos podem ser inseridos, observadas suas características mais gerais e salientes como espécie, tipo, forma, habitat entre outros. Ressalta-se também o caráter semântico agrupador e a significação mais abrangente de um termo (hiperonímico) sobre outros termos cuja referência remete ao todo ou a alguma parte ou característica do objeto ordenado nas diferentes classes de termos.

\section{Os termos $k \hat{a}, k t a ̂, k t \tilde{e}$ e nrõ nos topônimos xerente}

Para Tavares e Isquerdo (2006), o ato de nomear reflete a cultura e a imago mundi do denominador, por meio das escolhas dos designativos que identificam os referentes relacionados à realidade de cada grupo que tem a dimensão cultural da língua bastante evidenciada. As razões pelas quais o denominador batiza (usando mecanismos de uma dada língua) um lugar estão, de uma maneira ou de outra, ligadas a fatores culturais e, em relação às comunidades indígenas, encontram-se intrinsecamente ligadas ao ecossistema em que estão inseridos.

A proposta é descrever, neste primeiro momento, pelo menos os designativos dos grandes rios, lagoas, serras, morros e alguns nomes de aldeias haja vista a quantidade de 
topônimos xerente, grande para o espaço deste artigo. Assim, são descritos os topônimos ${ }^{3}$ : Arbo nĩkrpo wdê hu 'Ribeirão Vão Grande', Hêspo hu kâ (ou kuĩ wdê zakerê kâ) 'Ribeirão Bananal', Hêspo wawẽ kâ 'Ribeirão São Francisco', Kâa mrã (ou Kâ wawẽ) 'Rio Tocantins', Kâ wahârê 'Ribeirão Salto', Kâ wakdu 'Rio Preto', Kâ wakmõrê 'Rio Piabinha', Krãiti kâ 'Ribeirão Formiga', Kri rã 'Porto Nacional', Ktâ krê 'Aldeia Panela de Ferro", Ktâ waptkãze kâ 'Brejo da Anta', Ktẽ ka kâ 'Rio do Sono', Ktẽ krãikwa 'Serra do Carmo', Ktẽ krsukâ (ou Wdê ttê kâa) 'Rio dos Bois', Ktẽ pre 'Morro da Pedra Vermelha'. Descrevem-se os elementos formadores do designativo toponímico em ordem alfabética e em termos mórficos, pois a língua Akwe-Xerente tem características morfológicas predominantemente aglutinantes.

É conveniente ressaltar que, conforme Siqueira (2009), de certa forma, os termos de classe Akwe-Xerente atuam como classificadores em nível lexical e, morfologicamente, compõem-se (quase sempre justapostos) de: $\left(\mathrm{N}^{4}+\mathrm{N}\right),(\mathrm{N}+\mathrm{N}+\mathrm{N}),(\mathrm{N}+\mathrm{NI}+\mathrm{RVFA}),(\mathrm{N}$ + RVFA + N + DIM), (N + N + Com). Quando há no corpus a descrição fonética do dado, esta acompanha a forma gráfica.

Quadro 1 - Relação de alguns topônimos xerente

\begin{tabular}{|c|c|}
\hline Topônimo xerente & Topônimo oficial $^{5}$ \\
\hline $\begin{array}{l}\text { (1) Arbo nĩkrpo wdê hu } \\
\text { 'morcego-N + unha-NI + árvore-N + encher-RVFA' } \\
\text { Lit. 'árvore cheia de unhas de morcego' }\end{array}$ & 'Ribeirão Vão Grande' \\
\hline $\begin{array}{l}\text { (2) Hêspo hu kâr [hespo hu 'ki] } \\
\text { (bananal-N + encher-RVFA + água/rio-N) } \\
\text { Lit. 'rio cheio de bananas (bananal)' }\end{array}$ & 'Ribeirão Bananal' \\
\hline $\begin{array}{l}\text { (3) Hêspo wawe kâa [hespo vavẽ 'ki] } \\
\text { (bananeira-N + velho-MOD + água/rio-N) } \\
\text { Lit. 'rio de banana velhas' }\end{array}$ & $\begin{array}{l}\text { 'Ribeirão São } \\
\text { Francisco' }\end{array}$ \\
\hline $\begin{array}{l}\text { (4) Kâ wawe ou Kâ mrã [ki vauẽ kì m'hã] } \\
\text { (água/rio-N + velho-MOD } \\
\text { lit. 'rio velho' }\end{array}$ & "Rio Tocantins" \\
\hline $\begin{array}{l}\text { (5) Kâ wahârê } \\
\text { (água/rio-N + clarear-RVFA + leito-N + DIM) } \\
\text { Lit. 'rio leito pequeno e claro' }\end{array}$ & 'Ribeirão Salto' \\
\hline
\end{tabular}

\footnotetext{
${ }^{3}$ Opta-se pela forma ortográfica proposta por Krieger e Krieger (1994) já que se trata de nomes próprios (pois designam lugares) cuja forma gráfica já está mais ou menos consolidada.

${ }^{4}$ À guisa de legenda: ADV - advérbio, Class - classificador, Comp - comparativo, DIM - diminutivo, Ind indefinido, MOD - modificador, N - nome, NI - nome inalienável, NOM - nominalizador, RVFA - raiz verbal em função adjetiva.

${ }^{5}$ Considera-se como topônimo oficial os apontados em documentos e nos mapas como tal e ainda, aqueles com designação espontânea, isto é, são largamente conhecidos por um nome que não é o oficial.
} 


\begin{tabular}{|c|c|}
\hline $\begin{array}{l}\text { (6) } K \hat{a} \text { wakdu } \\
\text { (água/rio-N + 'k'- part. quantidade + capim-N) } \\
\text { Lit. 'rio grande quantidade de capim' }\end{array}$ & 'Rio Preto' \\
\hline $\begin{array}{l}\text { (7) Kâ wakmõrê } \\
\text { (água/rio-N + 'k'-part. quantidade + limpa-MOD + DIM) } \\
\text { Lit. 'água pouca e limpa' }\end{array}$ & 'Rio Piabinha' \\
\hline $\begin{array}{l}\text { (8) Krãiti kâ [krõjti. kì] } \\
\text { (formiga-N + água/rio-N) } \\
\text { Lit. 'rio formiga' }\end{array}$ & 'Ribeirão Formiga' \\
\hline $\begin{array}{l}\text { (9) Kri rã } \\
\text { (casa-N + branco-N) } \\
\text { Lit. 'casa do branco' }\end{array}$ & 'Porto Nacional' \\
\hline $\begin{array}{l}\text { (10) Ktâ krê } \quad \text { [kti kre] } \\
\text { (anta/animais comestíveis-N + vagina-N) } \\
\text { Lit. 'vagina da anta' }\end{array}$ & 'Aldeia Panela de Ferro' \\
\hline $\begin{array}{l}\text { (11) Ktâ wapt kãze kâ } \\
\text { (anta-N + nascimento-N + água/rio-N) } \\
\text { Lit. 'rio onde nasce a anta' }\end{array}$ & 'Brejo da Anta' \\
\hline $\begin{array}{l}\text { (12) Ktẽ ka kâ } \\
\text { (pedra-N + branca-MOD + água/rio-N) } \\
\text { Lit. 'Rio da pedra branca' }\end{array}$ & 'Rio do Sono' \\
\hline $\begin{array}{l}\text { (13) Kte krãikwa } \\
\text { (pedra-N + afiada-MOD) } \\
\text { Lit. 'pedra afiada }\end{array}$ & 'Serra do Carmo' \\
\hline $\begin{array}{l}\text { (14) Ktẽ krsu } \\
\text { (pedra-N + cortada-MOD) } \\
\text { Lit. 'pedra cortada' }\end{array}$ & 'Serra do Tabocão' \\
\hline $\begin{array}{l}\text { (15) Ktẽ krsu kâa } \\
\text { (pedra-N + cortada-MOD + água/rio-N) } \\
\text { Lit. 'rio da pedra cortada' }\end{array}$ & 'Rio dos Bois' \\
\hline $\begin{array}{l}\text { (16) Ktẽ pre } \\
\text { (pedra-N + vermelha-MOD) } \\
\text { Lit. 'pedra vermelha' }\end{array}$ & $\begin{array}{l}\text { 'Morro da Pedra } \\
\text { Vermelha' }\end{array}$ \\
\hline $\begin{array}{l}\text { (17) Nrõ zawi } \\
\text { (coco-N + estimar-RVFA) } \\
\text { Lit. 'coco estimado' }\end{array}$ & 'Aldeia Porteira' \\
\hline
\end{tabular}




\begin{tabular}{l|l}
\hline (18) Nrõrom zawre $k \hat{a}$ & 'Rio Providência' \\
(coco-N + coisa-Ind + grande-MOD + água/rio-N) & \\
Lit. 'coco algum do rio grande' & 'Ribeirão Maracujá' \\
\hline $\begin{array}{l}\text { (19) Nrõ wdê kâ } \\
\text { (coco-N + árvore-N + água/rio-N) }\end{array}$ & \\
\hline $\begin{array}{l}\text { Lit. 'rio da árvore de coco' } \\
\text { (20) Po rêrkêze } \\
\text { Lit. 'veado que cai rio abaixo' }\end{array}$ & 'Morro do Chapéu' \\
\hline
\end{tabular}

(Fonte: Siqueira, 2010)

\section{Análise dos dados}

Pela descrição apresentada no Quadro 1, observa-se que TC kâ reveste-se da função de "capa linguística" para denotar o acidente geográfico 'rio' como em: (2) Hêspo hu kâ 'Ribeirão Bananal', (3) Hêspo wawẽ kâ, 'Ribeirão São Francisco', (4) Kâ wawẽ ou Kâ mrã, 'Rio Tocantins', (5) Kâ wahârê 'Ribeirão Salto', (6) Kâ wakdu 'Rio Preto', (7) Kâ wakmõrê 'Ribeirão Piabinha', (8) Krãiti kâ 'Ribeirão Formiga', (11) Ktâ wapt kãze kâ 'Brejo da Anta', (12) Ktẽ ka kâ 'Rio do Sono', (15) Ktẽ krsu kâ 'Rio dos Bois', (18) Nrõrom zawre kâ 'Rio Providência', (19) Nrõ wdê kâa 'Ribeirão Maracujá'.

Em outras palavras, o processo pode ser explicado da seguinte maneira: todos os biofatos que se caracterizam pela presença da "água" (lagoas, rios, ribeirões, córregos) recebem a lexia $k a ̂$ que passa por um esvaziamento semântico: é o conceito genérico que, à maneira de um termo de classe, passa pela percepção do objeto; os biofatos são apreendidos do universo $\mathrm{real}^{7}$ pelo denominador que se apropria da lexia disponível no léxico da língua ( $k a ̂$ 'água') e, mais tarde, pelo uso reiterado do nome, torna-se o designativo toponímico do lugar. Assim, para os acidentes hídricos rio, ribeirão ou lagoa (por serem "água") recebem todos o TC $k \hat{a}$, como uma capa linguística.

Segundo Carvalhinhos (2003), o denominador usa uma lexia disponível e a atualiza muitas vezes primeiramente como lexema, ou seja, não há intencionalidade real de denominação, apenas o nome é utilizado numa situação enunciativa oral. Esse fenômeno pode ser encontrado principalmente em nomeação espontânea, como é, na verdade, o caso desses topônimos xerente que tem seu concorrente oficial, muitas vezes usado em detrimento do designativo que o falante escolheu para o lugar. Entretanto, a percepção do mesmo objeto por falantes de etnias diferentes resulta também em designações diferentes. As características físicas do biofato são apreendidas por recortes culturais diversos. A motivação subjacente aos respectivos topônimos não parte dos mesmos aspectos percebidos, pois, o que é saliente e percebido em uma cultura quase nunca corresponde ao que foi recortado pela outra.

\footnotetext{
${ }^{6}$ Zawre cuja transcrição é [zaure] 'grande' porque [zaure], com sufixo -re 'pequeno'.

${ }^{7}$ A percepção do objeto do universo real é, evidentemente, um recorte linguístico feito a partir da cosmovisão do grupo.
} 
Dessa forma, têm-se, às vezes, certa coincidência entre os topônimos xerente e os oficiais como em: (2) Hêspo hu kâ 'Ribeirão Bananal ${ }^{8}$ ', mas não (3) Hêspo wawe kâ 'Ribeirão São Francisco'. Há equivalência aproximada em (8) Krãiti kâ 'Ribeirão Formiga', que possui ainda a designação Nrõ zâ pre, algo como 'semente de coco vermelha', que pode ter a referencialidade em "formiga", já que para designar alguns insetos bem pequenos os xerente usam o TC $z \hat{a}[\mathrm{zi}]$ semente. Nos demais topônimos com o termo kâ, não há equivalência de nomes.

Em relação ao termo ktâ 'anta', não é possível afirmar com certeza que ele tenha passado pelo mesmo processo de $k \hat{a}$, já que $k$ tâ tem sido usado mais em referência a algum detalhe do biofato do que exatamente como um termo genérico em torno do qual se organizam as especificidades do objeto. Em (11) Ktâ wapt kãze kâ 'Brejo da Anta', por exemplo, o TC ktâ indica uma característica saliente do lugar "onde as antas nascem", o biofato "brejo" sendo novamente, denotado por kâa 'água'. Esse fato aponta ainda para a coincidência entre as designações xerente e oficial 'Brejo da Anta', mas não em (10) Ktâ krê 'Aldeia Panela de Ferro'.

O termo ktẽe, cujo sentido original é 'pedra' passou por um esvaziamento semântico para designar os biofatos 'serra' e 'morro' como nos dados de (12) a (16), isso porque esses acidentes geográficos têm em sua morfologia grandes rochas o que, para os xerente, é a característica mais saliente. Ocorre coincidência entre ambas as designações apenas em (16) Ktẽ pre 'Morro da Pedra Vermelha'. Em (13) Ktẽ krãikwa 'Serra do Carmo', (14) Ktẽ krsu 'Serra do Tabocão', esse termo entra na formação do composto para designar os acidentes referentes às formas topográficas serra, morro, colina. Já em (12) Ktẽ ka kâa 'Rio do Sono' e em (15) Ktẽ krsu kâ 'Rio dos Bois' esse termo não indica o biofato propriamente dito, mas parte da descrição feita do lugar, isto é, em (12), apresenta o rio das pedras brancas; em (15), indica rio das pedras cortadas ou afiadas.

Quanto ao termo nrõ, pode-se dizer também que tem um uso descritivo no sentido de apresentar alguma característica saliente do lugar nomeado como em (17) Nrõ zawi 'Aldeia Porteira', (18) Nrõrom zawre kâ 'Rio Providência' e (19) Nrõ wdê kâ 'Rio Maracujá'. Em (20) Po rêrkêze 'Morro do Chapéu', há evidências eminentemente descritivas sem referência ao biofato "morro".

\section{Considerações finais}

O estudo de toda toponímia xerente pode revelar muito sobre a visão de mundo desse povo uma vez que, no ato de nomeação, o denominador seleciona do objeto/lugar denominado as características percebidas como mais evidentes, mais salientes e marca-as como categorias, ou seja, utiliza recursos do sistema de classificação nominal, mediante o uso de termos de classe, classificadores ou mesmo nomes com função classificadora para assinalar as peculiaridades do objeto apreendidas pelo denominador no ato de nomeação. Por outro lado, dado o caráter inicial desta pesquisa, foi possível apenas a análise dos topônimos arrolados no Quadro 1.

$\mathrm{Na}$ formação do topônimo composto, às vezes, o TC tem a função de um elemento genérico com qual organiza os outros elementos, à semelhança de uma capa linguística que, uma vez usada, passa a designar todo acidente natural que tenha características

\footnotetext{
${ }^{8}$ Esse ribeirão tem também outra designação em xerente: Kuĩwdê zakerê kâ, que faz referência a árvores, não exatamente a bananeira ou bananal, [hes'po] e [hespo 'hu] respectivamente. Para banana, o termo é [hespo 'krã].
} 
semelhantes. O termo $k \hat{a}$, por exemplo, teve seu sentido original (água) esvaziado para denotar os acidentes hídricos em geral, rios, lagoas, ribeirões, córregos da área indígena xerente.

Com o termo ktẽ 'pedra', ocorreu o mesmo processo, quando o lugar designado são elevações do relevo, sejam serras ou morros. Nesses, ktẽ funciona como termo genérico para as denominações orográficas e utiliza, para marcar as características mais salientes do objeto, conforme dados (13), (14) e (16), com os modificadores krãikwa, krsu, pre respectivamente. Estes funcionam como termos específicos, constituem provavelmente a motivação para o designativo toponímico. Entretanto ktẽ não aparece em Po rêrkêze 'Morro do Chapéu', obviamente que outros aspectos do lugar chamaram mais a atenção do denominador.

Em (11), o topônimo Ktâ wapt kãze kâ tem sua motivação no fato de haver no lugar um número grande de antas, como um lugar onde elas nascem, mas o biofato brejo foi designado por kâ. O mesmo ocorre em Ktẽ ka kâa 'Rio do Sono', água que corre nas pedras.

Já o termo nrõ funciona nos topônimos compostos como elemento específico, lugar que, de alguma forma, faz referência a coco ou coqueiro.

Os topônimos xerente são o que Dick (2007) chama de topônimos de primeira geração ou topônimos étnicos, designados de maneira autóctone antes da chegada do branco às terras indígenas. Normalmente, os topônimos de segunda geração (os que são designados pelo branco) sobrepõem-se ao nome indígena.

$\mathrm{Na}$ verdade, os lugares xerente são conhecidos pela sociedade envolvente pelos topônimos oficiais (Rio Tocantins, Rio do Sono, Morro do Chapéu), cujas motivações perpassam outros aspectos, na maioria, fatores de ordem cultural diversos da visão de mundo do povo Akwe-Xerente como se pôde ver pela descrição apresentada no Quadro 1. Dada a situação de intenso contato interétnico, o que preocupa é estimar até quando os Akwe-Xerente vão continuar usando o próprio topônimo - criado dentro da língua indígena usando os recursos linguísticos disponíveis dessa língua.

\section{REFERÊNCIAS}

AIKHENVALD, A. Classifiers: a typology of noun categorization devices. Oxford: Oxford University Press, 2000.

BARBOSA, M. A. Lexicologia, lexicografia, terminologia, terminografia, identidade científica, objeto, campos de atuação. In: Anais do II Simpósio Latino-Americano de terminologia. Brasília, UnB. 1990.

CARVALHINHOS, P. de J. Onomástica e lexicologia: o léxico toponímico como catalisador e fundo de memória. Estudo de caso: os sociotopônimos de Aveiro (Portugal). Revista da USP, São Paulo, n. 56, p. 172-179, dez./fev. 2002-2003.

DELANCEY, S. Toward a history of Tai classifier systems. In: CRAIG, C. (Ed.). Noun classes and categorization. Amsterdam: John Benjamins Publishing Company, 1986. p. 437-452.

DICK, M. V. de P. do A. A motivação toponímica e a realidade brasileira. São Paulo: Edições Arquivo do Estado de São Paulo, 1990. 
DICK, M. V. de P. do A. Atlas toponímico do Brasil: teoria e prática II. Revista Trama, Cascavel, v. 3, n. 5, p. 141-155, $1^{\text {o }}$ sem. 2007. Disponível em <http://erevista. unioeste.br>. Acesso em: 28 set. 2011.

DICK, M. V. de P. do A. Etnia e etnicidade: um novo modo de nomear. In: ISQUERDO, A. N.; FINATTO, M. J. B. (org). As ciências do léxico: lexicologia, lexicografia, terminologia. vol. IV. Campo Grande: UFMS- MS, 2010. p. 177-197.

FONSECA, G. S. La gente pasa, los nombres quedan... Introducción en la toponimia. Lima: G. Herrera, 1997.

KRIEGER, W. B.; KRIEGER, G. C. Dicionário Escolar: xerente-português; portuguêsxerente. Rio de Janeiro: Junta das Missões Nacionais da Convenção Batista Brasileira, 1994.

LAKOFF, G. Classifiers as a reflection of mind. In: CRAIG, C. (Ed.). Noun classes and categorization. Amsterdam: John Benjamins Publishing Company, 1986.

LAKOFF, G.; JOHNSON, L. Philosophy in the flesh: the embodied mind and its challenge to western thought. New York: Basic Books, 1999.

LANGACKER, E. W. A study in unified diversity: english and mixtec locatives. In: ENFIELD, N. J. (ed.) Ethnosyntax: explorations in grammar and culture. New York: Oxford University Press, 2002. p. 138-161.

MATTHEWS, P. H. Morphology. Cambridge: Cambridge University Press, 1993.

MITHUN, M. The convergence of noun classification systems. In.: CRAIG, C. (Ed.). Noun classes and categorization. Amsterdam: John Benjamins Publishing Company, 1986. p. 379-398.

RODRIGUES, A. D. Línguas brasileiras: para o conhecimento das línguas indígenas. São Paulo: Loyola, 1994.

SIQUEIRA, K. M. de F. Considerações esparsas acerca do estudo lexical da língua Xerente. Trilhos, v. 5, n. 5, p. 26-33, 2007.

SIQUEIRA, K. M. de F. Descrição de nomes de partes do corpo em composições lexicais na língua Akwẽ-Xerente. In.: BRAGGIO, S. L. B.; SOUSA FILHO, S. M.(orgs.). Línguas e culturas Macro-Jê. Goiânia: Vieira, 2009. s.l, s.n., p. 273-296.

SIQUEIRA, K. M. de F. O sistema de classificação nominal Akwe-Xerente (jê): âmbitos de análise. 2010. Tese (Doutorado em Letras). Faculdade de Letras, Universidade Federal de Goiás, Goiânia, 2010.

SOUSA FILHO, S. M. Aspectos morfossintáticos da língua Akwẽ Xerente (Jê). 2007. Tese (Doutorado em Letras). Faculdade de Letras, Universidade Federal de Goiás, Goiânia, 2007.

TAVARES, M.; ISQUERDO, A. N. A questão da estrutura morfológica dos topônimos: um estudo na toponímia sul-mato-grossense. Revista Signum. Estudos de Linguagens, Londrina-PR, v. 9/2, p. 273-288, 2006.

Recebido em outubro de 2011.

Aprovado em novembro de 2012. 